\title{
Role Of Maternal Serum Homocysteine Level on Fetal Birth Weight
}

\author{
Afrina Begum ${ }^{1}$, Joya Sree Roy ${ }^{2}$, Nilufer Sultana ${ }^{3}$, Noorjahan Begum ${ }^{4}$ \\ ${ }^{1}$ Assistant Professor, ${ }^{2}$ Professor, ${ }^{3}$ Associate professor, Gynae \& Obs Dept. DMCH, Dhaka, ${ }^{4}$ Junior Consultant, Obs \& Gynae, Keraniganj Upazilla \\ Health Complex.
}

\begin{abstract}
:
Objective: The present study has been conducted to investigate the role of plasma homocysteine on neonatal birth weight. Methods: This prospective cross sectional analytical study was conducted in the inpatient department of obstetrics \& gynecology, Dhaka Medical College Hospital on 120 term, singleton pregnant women. Pregnant women with plasma total homocysteine $>15 \mu \mathrm{mol} / \mathrm{L}$ were termed as having hyperhomocysteinemia (case, $\mathrm{n}=25$ ), while women with plasma total homocysteine $\leq 15 \mu \mathrm{mol} / \mathrm{L}$ were considered as normal (control, $\mathrm{n}=95$ ). Neonatal birth weight was the main outcome variable which was compared between case and control groups. Result: The entire women in the case group were in their 3rd decades, while $80 \%$ of the control group were in this age range and $10 \%$ was below 20 and $10 \%$ above 30 years old. The cases were older than the controls $(25.6 \pm 2.0$ vs. $23.7 \pm 4.7$ years, $p=0.051)$. Over three-quarters $(76 \%)$ of the cases were SSC level educated, while majority $(84.2 \%)$ of the controls was primary level educated. Eighty percent of the neonates born of mothers with hyperhomocysteinemia were of low birth weight as opposed to only $9.5 \%$ in the control group. The mothers of case-group carry nearly $40(95 \%$ of $C I=11.5-126.4)$ times higher risk of having low birth weight babies than the mothers with normal homocysteine level. The mean birth weight of neonates of case group was observed to be significantly higher $(2.8 \pm 0.4 \mathrm{~kg})$ than that of control group $(2.2 \pm 0.4 \mathrm{~kg})$. Correlation between the two variables shows that as plasma homocysteine level of women increases the birth weight of neonates decreases bearing an inverse relationship between these two variables $(r=-0.326, p<0.001)$. Conclusion: Pregnant women with elevated plasma total homocysteine carry much higher risk of giving low birth weight babies than the women with normal or low level of total homocysteine. Thus, measuring total homcysteine during pregnancy is of much clinical importance as corrective measure could be taken to avert the adverse pregnancy outcome.
\end{abstract}

[BSMMU J $2013 ; 6$ (2) : 116-120]

\section{Introduction :}

The period of intrauterine growth and development is one of the most vulnerable periods in the human life cycle. The weight of the infant at birth is a powerful predictor of infant growth and survival, and is dependent on maternal health and nutrition during pregnancy. In developing countries, the majority of low birth-weight (LBW) infants because of intrauterine growth retardation (IUGR) are born small at term ( $>37$ weeks of gestation). Low birth weight leads to an impaired growth of the infant with its consequent risks of a higher mortality rate, increased morbidity ${ }^{1}$, impaired mental development ${ }^{2}$, and the risk of chronic adult disease. Infants who weigh 2,000-2,499 $\mathrm{g}$ at

Address for Correspondence: Dr. Afrina Begum, Assistant Professor Gynae \& Obs Dept. DMCH, Dhaka. birth have a four-fold higher risk of neonatal death than those who weigh 2,500-3,499 g. The more severe the growth restriction within the LBW category, the higher is the risk of death ${ }^{1}$. Maternal nutrition is, therefore, an important factor from public health point of view because it is susceptible to public health interventions.

Realizing this concept, recently interest has turned to specific micronutrients as possible limiting factors for foetal growth. It is now known that the prevalence of vitamin B12 deficiency is high in the Indian population ${ }^{4}$. It may be important to look into the potential role of vitamin B12 deficiency in elevating plasma homocysteine (Hcy) levels in pregnancy, and its implications for adverse pregnancy outcomes including low birth weight ${ }^{5}$. Methionine synthase is an enzyme which catalyzes the methylation of homocysteine to methionine using vitamin $\mathrm{B} 12$ as 
B12 as a cofactor and methyltetrahydrofolate as a substrate $^{6}$. Formation of methionine through this pathway represents an important component of the one-carbon metabolism for synthesis of phospholipids, proteins, myelin, catecholamines, DNA and RNA. A deficiency of either vitamin B12 and/or folic acid is likely to affect this pathway resulting in an elevation of plasma Hcy with a relatively low methionine level ${ }^{7}$. have reported that mothers in the highest tHcy (total homocysteine) tertile at 8 weeks of pregnancy had three times (OR: 3.26; 95\% CI: $1.05,10.13)$ and at labor had nearly four times (OR: 3.65 ; $95 \%$ CI: $1.15,11.56$ ) the odds of giving birth to a neonate in the lowest birth weight tertile. Dietary deficiencies for Vit-B6, B12, or folate are associated with elevated homocysteine concentration ${ }^{8}$.

Several factors increase plasma homocysteine level like genetic defects in homocysteine metabolism (CBS, MTHFR, Methionine synthase), nutritional deficiencies in vitamin cofactors (Folate, vitamin B12, vitamin B6), diseases (pernicious anemia, renal impairment, hypothyroidism, malignancy: acute lymphoblastic leukemia; carcinoma of the breast, ovary and pancreas, severe psoriasis), medications/toxins Folate antagonists- methotrexate, phenytoin, carbamazepine, vitamin B6 antagonist-theophylline, azarabine, oestrogen containing oral contraceptives, cigarette smoking, increasing age, male sex and menopause ${ }^{9}$. The small-for-date babies are usually ascribed to the small size and chronic undernutrition of mothers. Vitamin B12 and folate play an important role in nucleic acid metabolism cell growth and proliferation and are important determinants of fetal growth ${ }^{8,10}$.

From the above background information, it is evident that circulating total homocysteine may itself increase the risk of a wide range of abnormalities. Low birth-weight is one of them. The clinical implication of the present study lies in the facts that 1) low birth weight babies are at increased risk of higher morbidity and mortality and 2) hyperhomocystenemia can usually be corrected by supplementation with $\mathrm{B}$ vitamins including folic acid during pregnancy. So the findings derived from the study could be extrapolated to formulate a plan for supplementation of vitamin B12 and folate to pregnant women at risk of developing hyperhomocysteinemia.

\section{Methods :}

The present prospective study was carried out in the inpatient department of obstetrics \& gynecology, Dhaka Medical College Hospital over a period of 2 years between January 2009 to December 2010. The study population was comprised of pregnant women at their $3^{\text {rd }}$ trimesters attending Dhaka Medical College Hospital, Dhaka for antenatal check-up. Singleton pregnant women at their third trimester (between 37 - 40 weeks) with plasma total homocysteine $>15 \mu \mathrm{mol} / \mathrm{L}$ were considered as cases and with plasma total homocysteine $\leq 15 \mu \mathrm{mol} / \mathrm{L}$ were taken as controls. However, pregnant women with diabetes mellitus, chronic renal disease, chronic hyper tension, preeclampsia, thyroid disease and other medical diseases or with smoking habits were excluded from the study.

A total of 120 term pregnant women admitted in the labour ward for delivery were consecutively included in the study. All the study subjects were tested for plasma homocysteine level during their stay in the hospital. Of them 25 had tHcy $>15 \mu \mathrm{mol} / \mathrm{L}$ (designated as Case) and the rest 95 had tHcy $\leq 15 \mu \mathrm{mol} / \mathrm{L}$ (Control). Neonates weighing $<2500 \mathrm{~g}$ at birth were termed as low birthweight (LBW). Quantitative measurement of serum total homocysteine was estimated by fluorescence polarization immunoassay (FPIA) method by Abott AxSYM system analyzer ${ }^{11}$.

Collected data were processed using software SPSS (Statistical package for social sciences) version 11.5. The test statistics used to analyse the data were descriptive statistics, Chi-square $\left(\chi^{2}\right)$, Student t-Test and Odds Ratio with $95 \%$ confidence interval. Spearman correlation was done to see the relationship between maternal plasma homocysteine and neonatal birth weight. Level of significance was set at 0.05 and $\mathrm{p}$-value $<0.05$ was considered significant.

\section{Result :}

Age distributions of the study subjects demonstrate that all the women in the case group were in the range of $20-$ 30 years, while $80 \%$ of the control groups were in this age range and $10 \%$ was below 20 and $10 \%$ above 30 years of 
age. The cases were a bit older than the controls (25.6 \pm 2.0 vs. $23.7 \pm 4.7$ years, $p=0.051)$. More than threequarter $(76 \%)$ of the cases were SSC level educated while majority $(84.2 \%)$ of the controls was primary level educated. Cases were mainly rural residents $(64 \%)$ and the rest $36 \%$ were urban residents. Forty percent of the controls were from semi-urban area, $34.7 \%$ from rural and $25.3 \%$ from urban area (Table I).

Eighty percent of the cases gave birth to low birth weight neonates as opposed to only $9.5 \%$ of the controls. The risk having low birth weight babies in case group is more than $38(95 \%$ of $\mathrm{CI}=11.5-126.4)$ times higher than that in the control group. The mean birth weight of neonates of mothers with hyperhomcysteinemia (serum homocysteine $>15 \mathrm{nmol} / \mathrm{L}$ ) was observed to be significantly higher ( 2.8 $\pm 0.4 \mathrm{~kg}$ ) than that of mothers having normal homocysteine level $(2.2 \pm 0.4 \mathrm{~kg})$ (Table II). Correlation between the two variables shows that as plasma homocysteine level of women increases the birth weight of neonates decreases giving an inverse relation between the variables of interest $(r=-0.326, p<0.001)$ (fig. $1-2)$.

\section{Table-I}

Comparison of demographic features between case and control groups

\begin{tabular}{|c|c|c|}
\hline \multirow{2}{*}{ Demographic Feature } & Grol & p-value \\
\hline & Case (n \%) & Control (n \%) \\
\hline \multicolumn{3}{|l|}{ Age* (yrs.) } \\
\hline$<20$ & $0(0.0)$ & $9(9.5)$ \\
\hline $20-30$ & $25(100.0)$ & $76(80.0)$ \\
\hline$>30$ & $0(0.0)$ & $10(10.5)$ \\
\hline
\end{tabular}

\section{Table II}

Association between plasma homocysteine and birth weight of baby

\begin{tabular}{ccccc}
\hline Birth weight (kg) & Group & $\begin{array}{c}\text { Odds Ratio } \\
(95 \% \text { Cl of OR) })\end{array}$ & p-value \\
& $\begin{array}{cccc}\text { Case } \\
(\mathrm{n}=25)\end{array}$ & $\begin{array}{c}\text { Control } \\
(\mathrm{n}=95)\end{array}$ & & \\
\hline 2.5 & $20(80.0)$ & $9(9.5)$ & 38.2 & \\
& & & $(11.5-126.4)$ & $<0.001$ \\
22.5 & $5(20.0)$ & $86(9.5)$ & & \\
\hline
\end{tabular}

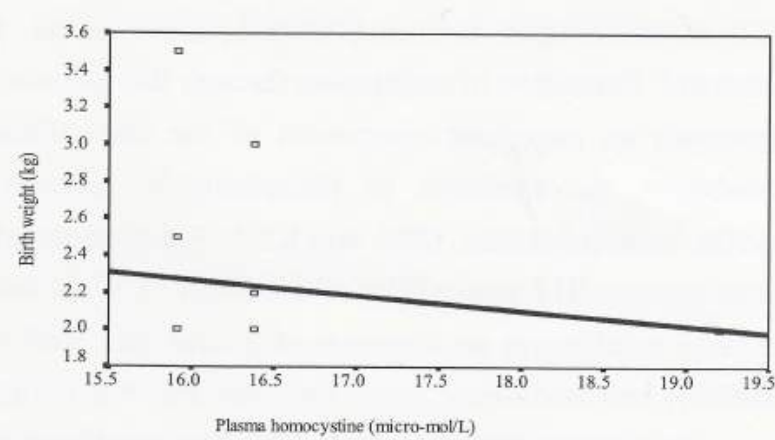

Fig. 1: Correlation between plasma homocysteine and birth weight of neonates (case group)

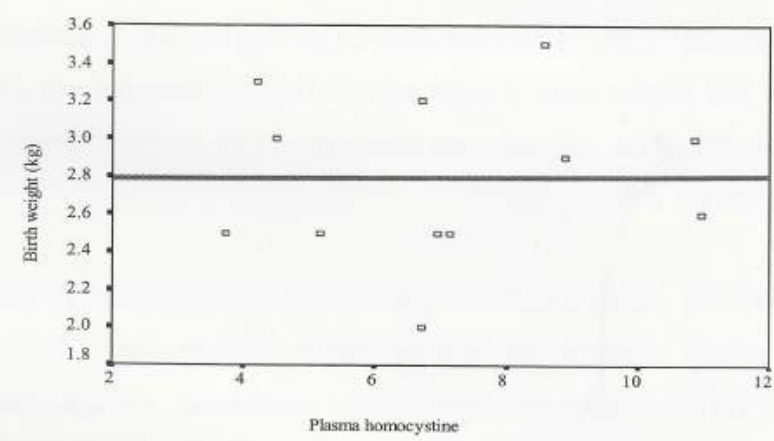

Fig. 2: Correlation between plasma homocysteine and birth weight of neonates (control group)

\section{Discussion :}

The present study aimed at finding the association between the level of maternal homocystine at term and neonatal birth weight included a total of 100 samples with single tone uncomplicated pregnancy. The study showed that pregnant women with hyperhomocysteinemia $(<15$ $\mu \mathrm{mol} / \mathrm{L}$ ) had neonates with mean birth weight $2.8 \mathrm{~kg}$, while mothers with normal homocysteine level $(>15$ $\mu \mathrm{mol} / \mathrm{L}$ ) had babies with average birth weight $2.2 \mathrm{~kg}$. Eighty percent of the babies born to hyperhomocysteinemic mothers were of low birth weight as opposed $10 \%$ of the babies born to mothers with normal homocysteine level. The risk of delivering a low birth weight baby by pregnant women with hyperhomocysteinemia was nearly $40(95 \%$ of $\mathrm{CI}=11.5-126.4)$ times higher than that by the mothers with normal homocysteine. This is in line with the studies done by Lindblad et $\mathrm{al}^{12}$ and Vollset et $\mathrm{al}^{5}$. Another study done by Yajnik et $\mathrm{al}^{13}$ in India reported the higher plasma tHcy concentrations were associated with lower birth weight. Murphy and associates ${ }^{7}$ in their study demonstrated that neonates of mothers in the highest tHcy tertile at 8 weeks of pregnancy had 3-fold (OR: 3.26; $95 \%$ 
CI: $1.05,10.13)$ and at labor had nearly four times (OR: $3.65 ; 95 \% \mathrm{CI}: 1.15,11.56)$ higher risk of giving birth to a neonate in the lowest birth weight tertile. Neonates of mothers in the highest tHcy tertile at labor weighed on an average $228 \mathrm{~g}$ less than those of mothers in the low and medium tertiles. They also showed that supplemented (with folate and vitamin B12) mothers had lower tHcy at labor than unsupplemented mothers, as did their neonates. Maternal and fetal tHcy was significantly correlated throughout the study. Neonates of mothers in the highest tertile of homocysteine weighed less. Supplemented mothers had lower tHcy at labor than unsupplemented mothers, as did their neonates. These findings are also consistent with findings of the present study where plasma homocysteine level of pregnant women and birth weight of neonates exhibited an inverse relationship indicating that higher the level of homocysteine the lower is the birth weight $(\mathrm{r}=-0.326, \mathrm{p}<0.001)$.

Shirin and associates ${ }^{14}$ in an attempt to find the association between plasma Hcy in pregnant women and IUGR enrolled 80 pregnant women with 30 having fetus with IUGR (case) and 50 without IUGR (control). Maternal Hcy of all the subjects were measured at $3^{\text {rd }}$ trimester and its effects on neonatal size were analyzed. The maternal Hcy of the IUGR cases was significantly higher than the controls. The IUGR babies born to cases had a significantly lower birth weight compared to the babies born to control mothers. The study concluded that raised homocysteine might be one of the risk factors for IUGR. In a prospective population-based study conducted near Pune (PMNS) between 1993-96, serum homocysteine level was measured in mothers of full-term small for gestational age (SGA) babies ( $<10^{\text {th }}$ centile) and in mothers of appropriate for gestational age (AGA) babies ( $>10$ th centile). Mothers of SGA babies were lighter and shorter than those of AGA babies ( $p<0.05$, both) and had higher plasma tHcy concentration $(\mathrm{p}<0.01)$. Total homocysteine concentrations were inversely related to plasma vitamin $\mathrm{B} 12$ and red cell folate concentrations $(\mathrm{r}=-0.5, \mathrm{p}<0.01$, both). Higher maternal plasma tHcy concentration was significantly associated with lower offspring birth weight ( $r=-0.28, p<0.05$ adjusting for maternal height, weight, gestation at delivery and the baby's gender). This effect was reduced by adjustment for red cell folate concentration. Other investigators also showed that mothers of SGA babies had higher plasma homocysteine concentration $^{15,16}$. It may, therefore, be important to look into the potential role of vitamin B12 deficiency in elevating plasma homocysteine (Hcy) levels in pregnancy, and its implications for adverse pregnancy outcomes including low birth weight. Methionine synthase is an enzyme which catalyzes the methylation of homocysteine to methionine using vitamin B12 as a cofactor and methyltetrahydrofolate as a substrate ${ }^{6}$. Formation of methionine through this pathway represents an important component of the one-carbon metabolism for synthesis of phospholipids, proteins, myelin, catecholamines, DNA and RNA. A deficiency of either vitamin B12 and/or folic acid is likely to affect this pathway resulting in an elevation of plasma Hcy with a relatively low methionine level.

One of our weaknesses in this study is the failure of maternal B12 and folic acid status assessment because of financial constraint. If we could do the cord blood assessment of B12, folic acid and Hcy, probably it would make out much better pathophysiological picture over this issue. We are optimistic that, in spite of these shortcomings the conclusions derived form this study on our population at least has given a tangible pulse of this big health problem and has created the window to visualize and conceptualize the magnitude of the problem.

The study concludes that pregnant women with elevated plasma total homocysteine carry much higher risk of giving low birth weight babies than the women with normal or low level of total homocysteine. Thus, measuring total homcysteine during pregnancy is of much clinical importance as corrective measure could be taken to avert the adverse pregnancy outcome.

\section{References:}

1. Ashworth A. Effects of intrauterine growth retardation on mortality and morbidity in infants and young children. Eur J Clin Nutr 1998;52(Suppl. 1):S34-S42.

2. Grantham-McGregor SM. Small for gestational age, term babies, in the first six years of life. Eur J Clin Nutr 1998;52(Suppl. 1):S59S64.

3. Barker DJP. Mothers, babies and health in later life. Churchill Livingstone, Edinburgh, 1998.

4. Refsum H, Yajnik CS, Gadkari M, Schneede J, Vollset SE, O rning $\mathrm{L}$, et al. Hyperhomocysteinemia and elevated methylmalonic acid indicate a high prevalence of cobalamin deficiency in Asian Indians. Am J Clin Nutr 2001;74:233-41. 
5. Vollset SE, Refsum H, Irgens LM, Emblem BM, Tverdal A, Gjessing HK. Plasma total homocysteine, pregnancy complications, and adverse pregnancy outcomes: the Hordaland Homocysteine Study. Am J Clin Nutr 2000;71:962-8.

6. Finkelstein JD. Methioine metabolism in mammals. J Nutr Biochem 1990;1:228-37.

7. Murphy MM, Scott JM, Arija V, Molloy AM, Fernandez-Ballart JD. Maternal homocysteine before conception and throughout pregnancy predicts fetal homocysteine and birth weight. Clin Chem 2004;50:1406-12.

8. Allen LH. Vitamin B12 metabolism and status during pregnancy, lactation and infancy. Adv Exp Med Biol 1994;352:173-86.

9. Finkelstein JD. The metabolism of homocysteine : pathways and regulation. Eur J Pediatr 1998;157(Suppl. 2):S40-S44.

10. Hoque MM, Bulbul T, Mahal M, Islam NAF and Ferdausi M. Serum homocysteine in pre-eclampsia and eclampsia. Bangladesh Med Res Counc Bull 2008;34:16-20.
11. Abott laboratories. Hornocysteine. Abott Park, USA, 2006.

12. Lindbland B, Zaman S, Malik A, Martin H, Iksirom A, Amu S et al. Folate Vitamine B12 and Homocysteine levels in South Asian women with growth retarded fetuses. Acta Obstet Gynecol Scand 2005;84:1055-61.

13. Yajnik CS, Deshpande SS, Panchandikar A, Naik SS, Deshpande JA, Coyaji, KJ et al. Meternal total homocysteine concentration and neonatal size in India. Asia Pac J Clin Nutr 2005;14:179-81.

14. Shirin F, Mehdi T, Alam M, Nath RK, Hoque MM. Effect of gestational homocysteine on fetal growth in Bangladeshi women. Ibrahim Med Coll J 2009;3:13-6.

15. Ueland PM. "Homocysteine species as components of plasma redox thiol status, Clin Chem 1995;41:340-2.

16. Refsum H, Fiskerstrand T, Guttormsen AB, Ueland PM. Assessment of homcysteine status. J Inherit Metab Dis 1997;20:286-94. 